\title{
Virtual Werribee: A planning support tool
}

\author{
$\underline{\text { M.Z. Abdul Ghani }}^{a}$, S. Datta ${ }^{\text {a }}$ and D. Beynon ${ }^{\text {a }}$ \\ ${ }^{a}$ School of Architecture and Building, Deakin University, Victoria \\ Email:mzabd@deakin.edu.au
}

\begin{abstract}
Virtual Werribee is collaborative research in applying 3-D modelling and visualisation as a planning support tool in comparison to 2-D plans and drawings. It was a joint initiative involving Deakin University and the Wyndham City Council to demonstrate the use of 3-D visualisation for planning process in the actual context of a planning authority in Australia. The objective of this project was to assist the council in preparing for the revised Local Structure Plan. By reconstructing the council's data into easily understood information, 3-D model and visualisation served as a verification and discussion tool for decision making. The integration of wider site context also provided a better understanding of the surrounding development areas. This could equip other stakeholders as well as the community to participate in council's planning agenda activities, such as increasing the urban density and building heights limit.
\end{abstract}

Virtual Werribee included the development planning agenda, categorised as new, re-development and hypothetical. The modelling process progressed with sufficient data from the council. Some changes to the initial plan were made, including the use of CAD modelling software instead of GIS software, and production of a block model with selected detail buildings, instead of a full draped 3-D model. The council decided that the block model would be sufficient for their planning purposes. This was determined while taking into consideration the available facilities at the council.

The potentials of the model as a planning tool were demonstrated in this paper, and further compared to the council's existing materials prepared by the project developers. The advantages of the 3-D interactive model and visualisation over the conventional materials have provided the council officer with a tool for better empowerment in the planning process. This was also evident in the increasing engagement level between the officer and the model as the process developed. As a result of this, the project scope has also expanded, finally covering the entire city.

While Virtual Werribee has the potential to better communicate council's planning agendas to the stakeholders and the community, the key factor, coupled with its visualisation components, was its interactive capability. Property layers with aerial site image that provided a realistic background served as a virtual city platform for different users. Although limited in its analytic capability found in GIS software, this model offered high visualisation content to assist visual impact assessment through its interactive mode along with a series of still images and a simulation movie.

Keywords: 3-D modelling, visualisation, planning support tool, Geographic Information System (GIS) 


\section{INTRODUCTION}

Virtual Werribee is a visualisation environment to address the needs for modelling urban growth (Batty et al., 2000; Brail \& Klosterman, 2001; Fragkias \& Seto, 2007) and for developing the application skills of 3-D modelling as a planning support tool between Deakin University and the Wyndham City Council. The objective is to assist the council in pursuing their planning agendas, including preparing and revising their local structure plan. It provides the council with an improved planning tool to support decision making and planning consultation among the involved parties. This would be the council's first experience in exploring a 3-D model which is capable of animating scenes, perform multiple spatial queries, shadow analysis, and various scenario based analysis (Shiode, 2001).

By reconstructing the council's data into easily understood information, the visualisation model (Kim \& Bejleri, 2005) served as a verification and discussion tool to facilitate decision making and provide better understanding among decision makers and stakeholders in the development proposals. In addition, the integration of the wider site context with the model could further improve this understanding. In comparison to conventional planning materials such as 2-D plans, drawings and 3-D physical model, the digital model could also equip the community with better understanding to participate in the planning activities organised by the council to pursue its planning agenda, such as increasing urban density and building heights.

In updating its local planning strategies to bring better planning for Werribee, the Wyndham City Council has taken into account the State Government Strategic Plan which included the State's key policy statement for metropolitan areas known as Living Suburbs (Wyndham City Council, 1999). In this context, eight general strategies have been defined for Werribee. They are; rapid population growth, location of growth, major industrial and employment areas, transport, infrastructure, rural areas, environment, and urban design and image (Wyndham City Council, n.d.). These issues have been addressed in the working draft of the Werribee City Centre Vision which included several development proposals, categorised in this research as new, redevelopment and hypothetical.

\section{PROCESS}

The earlier proposal of Virtual Werribee concentrated on the city centre and the main street, which is Watton Street. During the initial meeting, research scope, samples of similar works, and expectations were presented to the council officer. It included developing a 3-D base model for Werribee, including land contour, river, railway line and three proposals; the River Bank Mall, the Piazza and a Pedestrian Bridge.

While the aim is to disseminate development planning to the stakeholders, means to communicate the materials have been explored in this research. The result is a presentation comprising three components; an interactive SketchUp ${ }^{\circledR}$ model which the viewer could 'walk around' (Figure 1), a series of rendered images of the entire city and the proposed developments (Figure 2); and a 3-D simulation movie integrating Google Earth ${ }^{\circledR}$ (Figure 3). The development of the Virtual Werribee took approximately sixty hours within a period of eight months which started from the initial meeting.

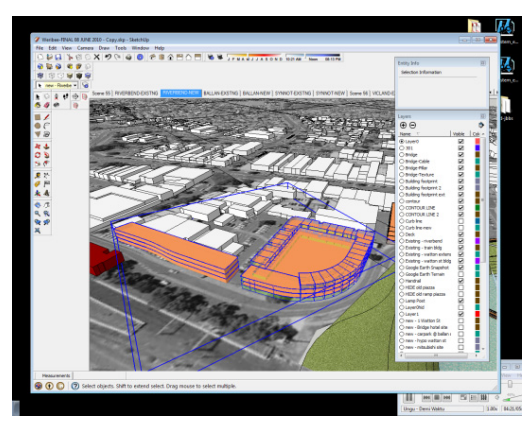

Figure 1. SketchUp® model

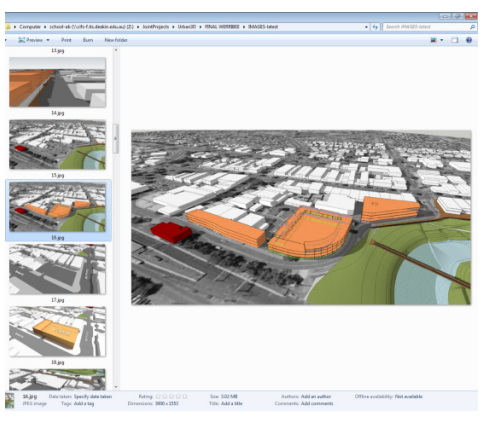

Figure 2. Rendered images

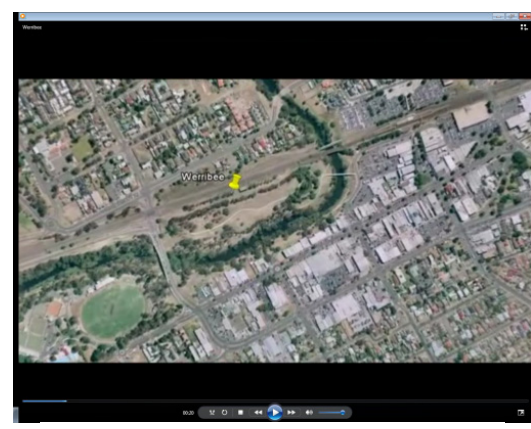

Figure 3. Simulation movie

The set level of detail included smooth, and not stepped, terrain contour of up to one metre, and smooth road. The building blocks would be draped with facade pictures, and included other recognisable elements such as levels and openings. While the initial schedule was to build a block model, some buildings required further details. Aimed at achieving effectiveness to communicate council's intentions as well as being resourceful, clear distinctions of areas which required detail and massing were identified. When the block model was completed, the officer decided to discontinue with the plan to drape the entire building blocks with facade 
images. Instead, some building blocks which demanded more attention were applied with texture details. The officer considered that the block model would be sufficient for studying and demonstrating their planning intentions as stakeholders were generally more interested to know, for example, whether the new development would obstruct their views.

\subsection{Data acquisition}

The initial documents for data processing involved a digital copy of satellite images and aerial perspectives of the entire city. The hardcopy materials included a master plan, development planning proposal reports and drawings of two proposals prepared by the appointed project developers. These were followed by digital drawings in CAD and PDF formats, as well as GIS data property in GeoMedia ${ }^{\circledR}$. The additional photographs of a physical massing model assisted us in working with the complex multi level and height of the River bank Mall involving existing and new building blocks on a sloping site.

We found that the level of detail and accuracy in the materials we received from the council were satisfactory for reconstructing 2-D into a 3-D model. The high resolution aerial images provided us with precise building footprints for our laborious digitising process of developing the building blocks. The CAD terrain drawing also enabled us to develop a contoured base model. The location of trees in the CAD drawings also enabled us to position gum trees onto the model. To maintain a workable file size for faster uploading, we have chosen to use intersected images of trees rather than a full 3-D tree model.

\subsection{Data reconstruction and visualisation}

The SketchUp ${ }^{\circledR}$ model contained land boundaries, terrain contours, roads, curbs, street furniture, trees, rivers, parking areas, existing buildings and different options of the proposed developments. These attributes were placed in different property layers in different colours and titles. Within the interactive mode of SketchUp ${ }^{\circledR}$ version 7 , multiple views of the proposed developments could be generated by switching between different layers. These included layers of the existing and new buildings which would allow the viewers to experience the virtual transformation from the existing to new and subsequently to the hypothetical development. The aerial image of Werribee from Google Earth ${ }^{\circledR}$ was merged at the background to provide a more realistic representation of the cityscape and visually suggest how the new development would fit within the whole site context.

While the views from the interactive model would be sufficient for understanding the spatial design, the series of rendered images provided clearer snapshots of the model. These images were made accessible as they could be easily viewed, scaled or transferred into reports. Printed images could also be sketched upon, particularly to accommodate those who have no access to computers. In a two-minute video, the simulation movie of Werribee combined the readily available 3-D Melbourne in Google Earth ${ }^{\circledR}$. The animated flying scene demonstrated the proximity between the Melbourne city centre and Werribee as an option to the numeral distance count.

As the modelling progressed along the consultations between the council and the project developers, many design changes were made to the model. In communicating these changes, we have emailed saved images of the affected design to the council officer for further clarification and confirmation. He would then scan these images and write notes on them before emailing them back to us for further modifications. For bigger files, we utilised DropBox ${ }^{\circledR}$.

\subsection{3-D GIS}

Attempting to integrate 3-D modelling with the GIS system, this research started by using ArcGIS ${ }^{\circledR}$ version 9.2. Data layers from the council were transferred into ArcMap and viewed in ArcScene, along with the building blocks that were earlier extruded in SketchUp ${ }^{\circledR}$ from the digitised building footprints. The council officer was convinced with the outcome and of the benefits of ArcGIS ${ }^{\circ}$, which may be used in future for by other councils, along with other powerful software. He was particularly impressed with the GIS layer selection

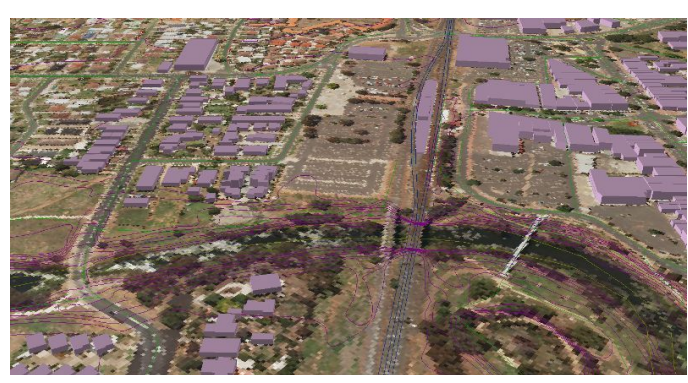

Figure 4. View of 3-D Werribee in ArcScene integrating 3-D buildings and background site image (Figure 4). 
He also thought that the data layers in ArcMap could better connect to decision makers such as planners and engineers, while architects would be more familiar with the modelling software. In accommodating the whole planning team, he believed that ArcScene would be more friendly and engaging. However, taking into consideration the available facilities at the council, the decision was made to entirely work with SketchUp ${ }^{\circledR}$ although it lacks the analytic capability of GIS software.

\subsection{Interest}

As the whole model began to take shape, the officer became more convinced of the potentials in the model for planning as described in Table 1. As a result of this, the research scope expanded, with ten more proposals covering almost the whole area of Werribee. He was also more engaged in the discussion than previously, when we were dealing with technical reports and 2-D drawings in different forms. It was also observed that his engagement level increased with the model, presumably because he could better relate to the more developed model compared to earlier in the process. At this stage, he was contributing to the model development by refining and adding materials while experiencing manoeuvring around the virtual model.

Table 1. Development of Virtual Werribee

\begin{tabular}{|c|c|c|}
\hline \multicolumn{2}{|c|}{ Liason with council } & \multirow{2}{*}{$\begin{array}{l}\text { Observation on officer's interest } \\
\text { The officer was very excited as there has not been a virtual exhibition of } \\
\text { Werribee from the officer. }\end{array}$} \\
\hline $1 \mathrm{st}$ & Meeting & \\
\hline 2 nd & Discussion & $\begin{array}{l}\text { The officer was impressed with 3-D GIS demonstration using ArcGIS }{ }^{\circledR} \\
\text { and SketchUp }{ }^{\circledR} \text {. }\end{array}$ \\
\hline 5 th & $\begin{array}{l}\text { Progress presentation } \\
\& \text { discussion }\end{array}$ & $\begin{array}{l}\text { At the massing model stage: the officer was already pleased to be able to } \\
\text { visualise the entire city in } 3 \text {-D for the first time. As the model progressed, } \\
\text { more requirements were demanded by the officer. }\end{array}$ \\
\hline 7 th & $\begin{array}{l}\text { Continuous } \\
\text { consultation through } \\
\text { email and Dropbox }{ }^{\circledR}\end{array}$ & $\begin{array}{l}\text { The officer became more confident and engaged in the discussion than } \\
\text { previously. (Discussion tool) }\end{array}$ \\
\hline 8 th & $\begin{array}{l}\text { Progress presentation } \\
\& \text { discussion. }\end{array}$ & $\begin{array}{l}\text { Some inconsistencies and discrepancies in the consultant's drawings were } \\
\text { discovered and highlighted in 3-D to the officer for further consultation } \\
\text { with the project developer. Options using 3-D were also presented. } \\
\text { (Verification tool) }\end{array}$ \\
\hline 9th & $\begin{array}{l}\text { Progress presentation } \\
\& \text { discussion }\end{array}$ & $\begin{array}{l}\text { The officer was very pleased to visualise the entire city within a more } \\
\text { realistic background integrating Google Earth's aerial image. Switching } \\
\text { between layers enabled the officer to view the impact of proposed } \\
\text { development in different scenarios, including existing and future. }\end{array}$ \\
\hline 10th & Extensive discussion & $\begin{array}{l}\text { Recognising the benefits of the model, the officer decided to extend the } \\
\text { project. }\end{array}$ \\
\hline 11th & $\begin{array}{l}\text { Progress presentation } \\
\& \text { discussion }\end{array}$ & The officer became progressively engaged with the model. \\
\hline 12th & Finalising the project & $\begin{array}{l}\text { The officer found that the combination of SketchUp }{ }^{\circledR} \text { model with Google } \\
\text { Earth's 3-D model as engaging, attractive and friendly. }\end{array}$ \\
\hline 13th & $\begin{array}{l}\text { Final product } \\
\text { submission }\end{array}$ & Research completed. \\
\hline
\end{tabular}

\section{POTENTIALS}

\subsection{Development; new, re-development and hypothetical}

In facilitating the council in revising Werribee's local plan, the potentials of the Werribee 3-D model and its visualisation techniques as a verification and discussion tool were explored and compared to the conventional 
methods such as 2-D plans and drawings. This was demonstrated in several proposals outlined for the revised local plan; categorised as new, re-development and hypothetical.

\subsection{Decision making tool}

3-D Werribee has the potential to serve as a tool to understand complex planning information and motivate decision makers to arrive at better decisions to enhance living qualities and manage the built environment (Emem \& Batuk, 2004). The interactive layer property options showed the visual impact of proposed hypothetical development to the surrounding areas, as shown in Figure 6 and 7. Combining Google Earth's aerial image as the background provided a more realistic site context. Another benefit of the model was transparency control in visualising proposed development in relation to existing buildings. This was carried out by overlapping a proposed development over the existing grey buildings while reducing the opacity of new development layer, showed in a different colour. In comparison to the council's 2-D documents, these capabilities could assist the stakeholders in decision making, for example, in making better judgements about whether such a development would benefit the community or otherwise.

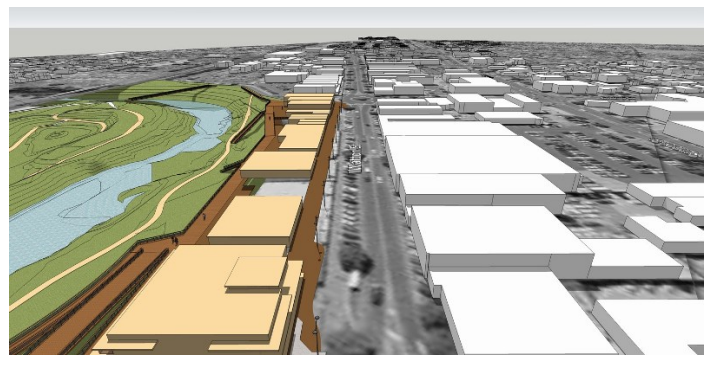

Figure 6. Existing development

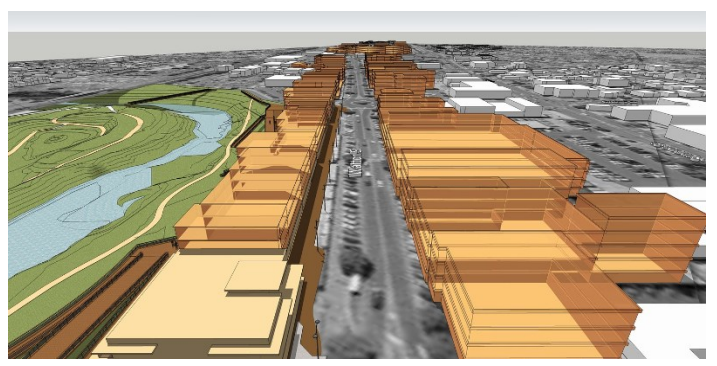

Figure 7. Hypothetical development

\subsection{Comparison; Existing 3-D interactive visualisation and council's documents}

Planning materials referred by the council which included 2-D drawings and 3-D physical model were compared to Virtual Werribee as described in Table 2.

Table 2. Comparison: council's documents with Virtual Werribee

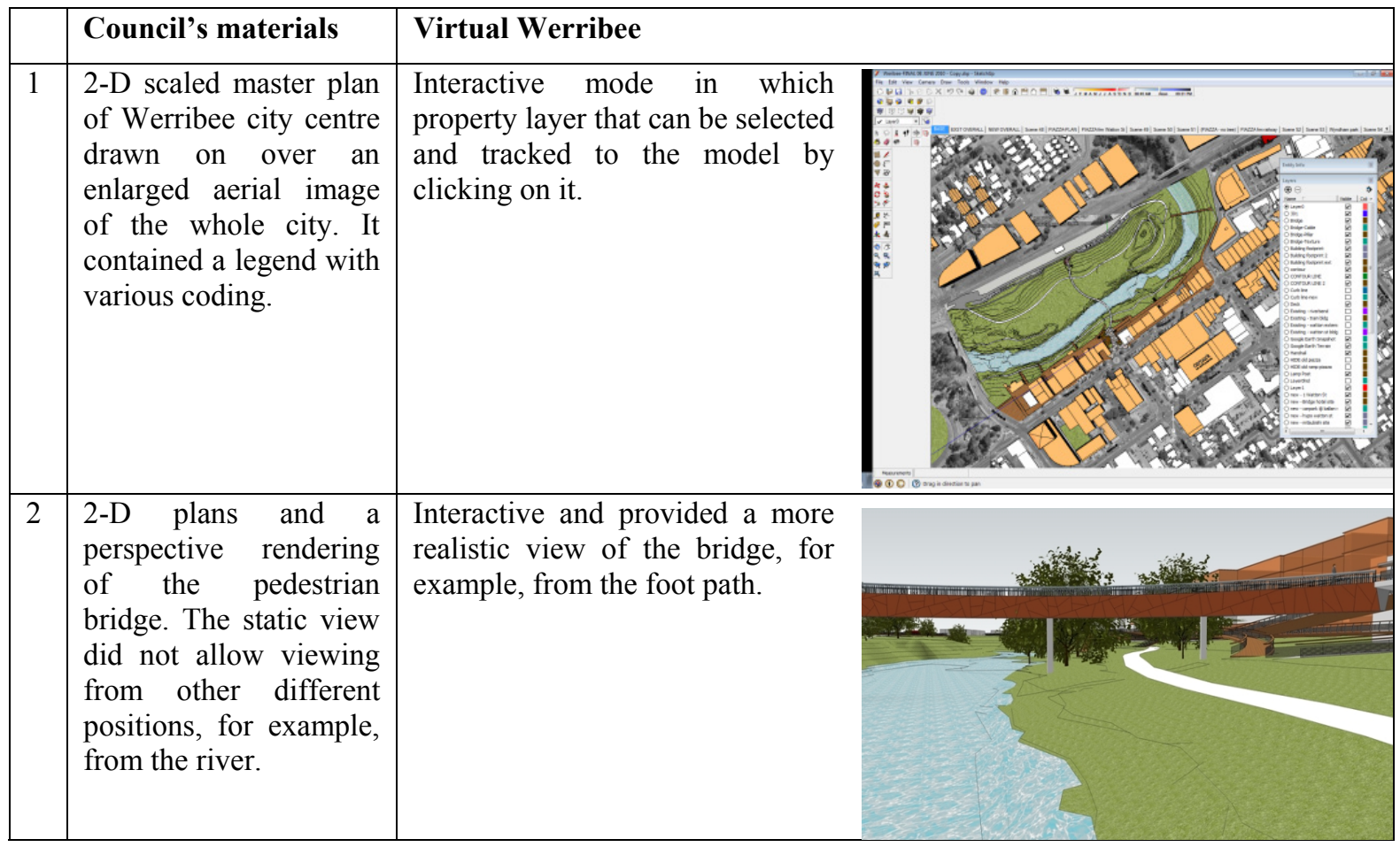




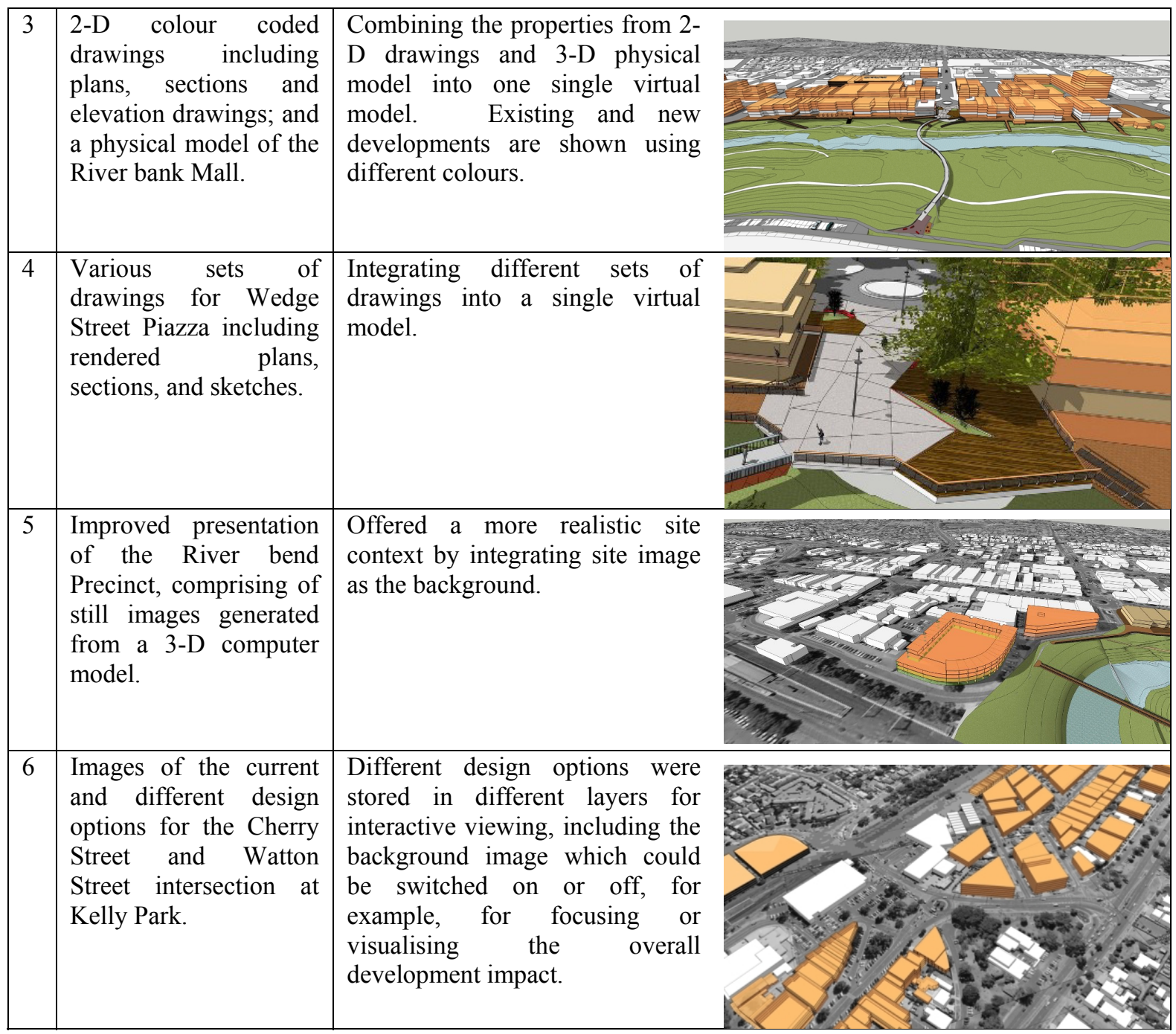

While the physical model took a long time to build, it was quickly out-dated, and required much storage space. On the other hand, while it did not require physical space, its digital representation is less likely to be out-dated as new layers can continuously be added to incorporate new design changes. Project developers have often used 3-D model as a tool to project their planning intentions, sometimes convincing the council and stakeholders by pre rendering selected views. On the other hand, if the council was in control of a similar model, they could use it to verify the information provided.

\subsection{Discussion and verification tool}

3-D Werribee provided the council with a discussion tool for the process of revising Werribee's local plan. The interactive model provided a platform for communicating ideas between the council and project developers.

During the process, inconsistencies and errors were discovered in the developer's drawings. As shown in Figure 5, there was insufficient room height clearance between the timber deck and staircase. Using 3-D modelling, these problems were better highlighted to the council

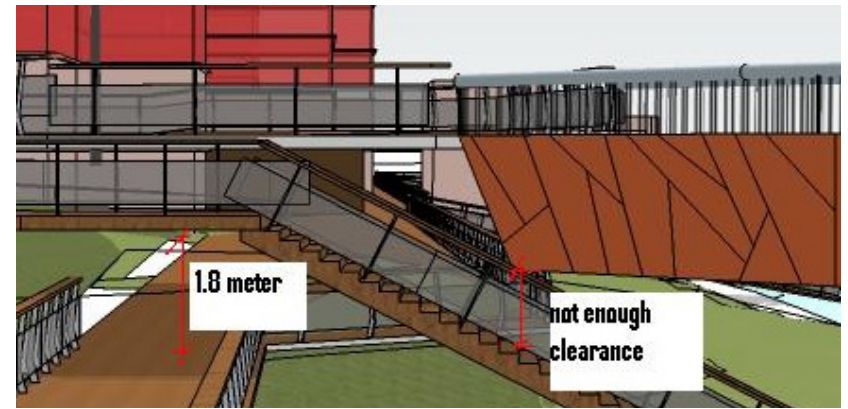

Figure 5. Design error highlighted in 3-D modelling MIY officer. Design options using the same method were also presented to the officer for further negotiation with the developers. 


\section{CONCLUSION}

This paper demonstrated the actual process of developing a 3-D model for planning applications in the context of a local planning authority in Australia. It explored the use of interactive 3-D model to assist the Wyndham City Council in preparing for the revised local structure plan by transforming existing conventional planning materials into easily understood form. The process involved data acquisition, data reconstruction and visualisation methods to communicate development planning proposals (categorised as new, re-development and hypothetical). Some amendments to the initial research proposition were made during the process to suit the planning requirements, involving level of detail, GIS software and research scope. Although limited in analytic capability to that generally found in GIS software, this model offered high visualisation content to assist visual impact assessment (Rafi \& Rani, 2008) through its interactive mode, along with a series of still images and a simulation movie.

Among the potential uses for decision making of Virtual Werribee, which were demonstrated in this research, are as a discussion and verification tool. As a discussion tool, the model's interactive capability enabled showing multiple views of planning scenarios. The background image, by providing a realistic site context, could further enhance the understanding of the proposed development, and improve discussion. The model also better highlighted design discrepancies compared to 2-D drawings. This could be a tool for planners to verify developer's planning proposal, thus supporting the council with by further empowering them in decision making. In this matter, the key issue lies in the ownership and control of the model. This could be a strong motivation for local councils to start developing 3-D virtual models. The physical model also takes a long time to build, it is quickly out-dated, and requires much storage space. While it does not require physical space, its digital representation is less likely to be out-dated as new layers can continuously be added to incorporate new design changes.

Virtual Werribee is anticipated to better communicate development planning agendas to the stakeholders and the community, as compared to 2-D text based materials and 3-D physical models. Unlike these conventional planning materials, 3-D model and visualisation technique, including interactive component, can better engage planners, and presumably other team members, as observed in this research. This research has demonstrated that the experience of using the model has increased the council officer's level of engagement with the modelling process. This form of communication can also be used by other agencies and team players in participatory activities, such as meetings with the council to discuss development planning. However, although the intentions of Virtual Werribee included assisting the council in meetings with the stakeholders and the community, this actual role could not be demonstrated in the duration of this research.

\section{ACKNOWLEDGMENTS}

The Virtual Werribee was funded by the Wyndham City Council, Australia. The authors from Deakin University's A+B Digital Media Laboratory acknowledge the efforts of Dr Craig Toussaint of the Economic Development Unit who has provided enormous support including planning materials and time for this research.

\section{REFERENCES}

Batty, M, Chapman, D, Evans, S, Haklay, M, Kueppers, S, Shiode, N, Smith, A \& Torens, PM (2000). Visualizing the city: communicating urban design to planners and decision-makers. Center for Advanced Spatial Analysis, University of College London, London.

Brail, RK \& Klosterman, RE (eds) (2001). Planning support systems: integrating geographic information systems, models and visualisation tools, ESRI Press, California.

Emem, O \& Batuk, F (2004). Generating precise and accurate 3D city models using photogrammetric data. ISPSR 2004, Istanbul, pp. 431-436.

Fragkias, M \& Seto, KC (2007). Modeling urban growth in data-sparse environments: a new approach. Environmental and Planning B: Planning and Design 2007, 34, 858-883.

Kim, D-H \& Bejleri, I (2005). Using 3D GIS simulation for urban design. ESRI User Conference, San Diego, California, 4th Nov 2005.

Rafi, A \& Rani, RM (2008). Visual impact assessment (VIA): a discussion on computer-based methodologies used for urban streetscapes. International Conference on Environment Research and Technology (ICERT 2008), Penang, Malaysia, 28-30th May, 2008.

Shiode, N (2001). 3D urban models: recent developments in the digital modelling of urban environments in three-dimensions. GeoJournal, 52, 263-269. 
Abdul Ghani et al., Virtual Werribee: a planning support tool

Wyndham City Council (1999). Wyndham planning scheme; key issues. WC Council (ed.), Wyndham City Council, Wyndham, 5.

Wyndham City Council (n.d). Municipal strategic statement, Wyndham City Council. Retrieved 16th December 2010, <http://www.wyndham.vic.gov.au/building_planning/strategic/municipalstrategic $>$. 